Bryn Mawr College

Scholarship, Research, and Creative Work at Bryn Mawr

College

2011

\title{
Intramolecular and intermolecular contributions to the barriers for rotation of methyl groups in crystalline solids: Electronic structure calculations and solid state NMR relaxation measurements
}

Xianlong Wang

Peter A. Beckmann

Bryn Mawr College, pbeckman@brynmawr.edu

Clelia W. Mallory

Arnold L. Rheingold

Antonio G. Pasquale

See next page for additional authors

Let us know how access to this document benefits you.

Follow this and additional works at: http://repository.brynmawr.edu/physics_pubs

Part of the Physics Commons

\section{Custom Citation}

X. Wang, P.A. Beckmann, C.W. Mallory, A.L. Rheingold, A.G. DiPasquale, P.J. Carroll, F.B. Mallory. 2011. "Intramolecular and intermolecular contributions to the barriers for rotation of methyl groups in crystalline solids: Electronic structure calculations and solid state NMR relaxation measurements." The Journal of Organic Chemistry 76.13: 5170-5176. 


\section{Authors}

Xianlong Wang, Peter A. Beckmann, Clelia W. Mallory, Arnold L. Rheingold, Antonio G. Pasquale, Patrick L. Carroll, and Frank B. Mallory 
Intramolecular and Intermolecular Contributions to the Barriers for Rotation of Methyl Groups in Crystalline Solids: Electronic Structure Calculations and Solid State NMR Relaxation Measurements

http://pubs.acs.org/doi/abs/10.1021/jo2006818

Xianlong Wang, ${ }^{\dagger, \S}$ Peter A. Beckmann, ${ }^{\ddagger}$ Clelia W. Mallory, ${ }^{\dagger}, \#$ Arnold L.

Rheingold, ${ }^{\text {II }}$ Antonio G. DiPasquale, ${ }^{\text {II, }}{ }^{\text {Patrick J. Carroll, }}{ }^{\#}$ and Frank B. Mallory*,†

${ }^{\dagger}$ Department of Chemistry, Bryn Mawr College, Bryn Mawr, Pennsylvania 19010-2899, United States. ${ }^{\S}$ University of Electronic Science and Technology of China, Chengdu, China 610054. ${ }^{\ddagger}$ Department of Physics, Bryn Mawr College, Bryn Mawr, Pennsylvania 19010-2899, United States. *Department of Chemistry, University of Pennsylvania, Philadelphia, Pennsylvania 19104-6323, United States. IIDepartment of Chemistry and Biochemistry, University of California, San Diego, 9500 Gilman Dr., La Jolla, California 92093-0358, United States.

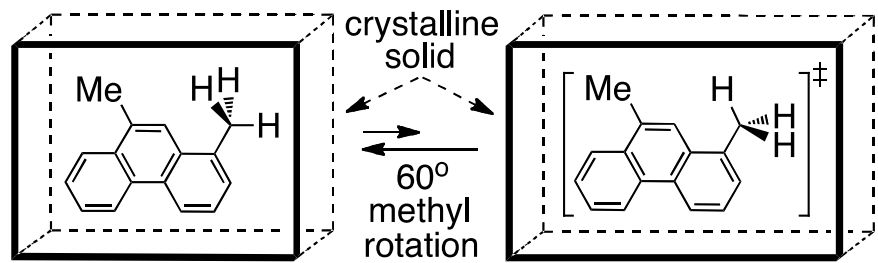

calculated potential energy barrier $=2.4 \mathrm{kcal} / \mathrm{mol}$ experimental activation energy $=2.2 \mathrm{kcal} / \mathrm{mol}$

\begin{abstract}
The rotation barriers for ten different methyl groups in five methylsubstituted phenanthrenes and three methyl-substituted naphthalenes were determined by ab initio electronic structure calculations, both for the isolated molecules and for the
\end{abstract}


central molecules in clusters containing 8-13 molecules. These clusters were constructed computationally using the carbon positions obtained from the crystal structures of the eight compounds and the hydrogen positions obtained from electronic structure calculations. The calculated methyl rotation barriers in the clusters $\left(E_{\text {clust }}\right)$ range from 0.6 $\mathrm{kcal} / \mathrm{mol}$ to $3.4 \mathrm{kcal} / \mathrm{mol}$. Solid-state ${ }^{1} \mathrm{H}$ NMR spin-lattice relaxation rate measurements on the polycrystalline solids gave experimental activation energies $\left(E_{n m r}\right)$ for methyl rotation in the range from $0.4 \mathrm{kcal} / \mathrm{mol}$ to $3.2 \mathrm{kcal} / \mathrm{mol}$. The energy differences $E_{\text {clust }}-$ $E_{n m r}$ for each of the ten methyl groups range from $-0.2 \mathrm{kcal} / \mathrm{mol}$ to $+0.7 \mathrm{kcal} / \mathrm{mol}$, with a mean value of $+0.2 \mathrm{kcal} / \mathrm{mol}$ and a standard deviation of $0.3 \mathrm{kcal} / \mathrm{mol}$. The differences between each of the computed barriers in the clusters $\left(E_{\text {clust }}\right)$ and the corresponding computed barriers in the isolated molecules $\left(E_{\text {isol }}\right)$ provide an estimate of the intermolecular contributions to the rotation barriers in the clusters. The values of $E_{c l u s t}-$ $E_{\text {isol }}$ range from $0.0 \mathrm{kcal} / \mathrm{mol}$ to $1.0 \mathrm{kcal} / \mathrm{mol}$.

\section{INTRODUCTION}

We have employed ab initio electronic structure calculations to obtain values of the energy barriers for the rotations of ten different methyl groups in the crystals of five methyl-substituted phenanthrenes and three methyl-substituted naphthalenes. We began by calculating the molecular structures of the eight isolated molecules, whose names, acronyms, numbering schemes, ${ }^{1}$ and (except for 4,5-DMP) ground-state methyl conformations are shown below. We then calculated the molecular structures for clusters 
containing 8-13 molecules of each of these compounds. These clusters were constructed computationally to have the same packing patterns as those found for the eight compounds by single-crystal X-ray diffraction or single-crystal neutron diffraction measurements by us or by others..$^{2-5}$ We tested the dependability of our computational methods by comparing the calculated values of the energy barriers for methyl rotation in the clusters with the experimental values of the activation energies for methyl rotation in the crystals of these eight compounds as determined by measurements of the solid-state NMR ${ }^{1} \mathrm{H}$ spin-lattice relaxation rates as a function of temperature and NMR frequency. ${ }^{6-9}$ Our experimental design is based on three assumptions: (1) that the calculated barrier for methyl rotation in an isolated molecule provides an appropriate measure of the combination of intramolecular steric and intramolecular electronic effects that contribute to the destabilization of the transition-state conformation relative to the ground-state conformation of the isolated molecule; (2) that the computationally constructed clusters each contain a sufficient number of molecules surrounding the central molecule to create a local environment for that molecule that is a reasonable simulation of the local environment of an individual molecule in the actual crystal; and (3) that if the groundstate conformation of the methyl group in the central molecule in a cluster is sufficiently similar to the ground-state conformation of the methyl group in the isolated molecule, then an approximate estimate of the intermolecular contribution to the methyl rotation barrier in the crystal can be obtained by subtracting the calculated barrier for the isolated molecule from the calculated barrier for the central molecule in the cluster. 


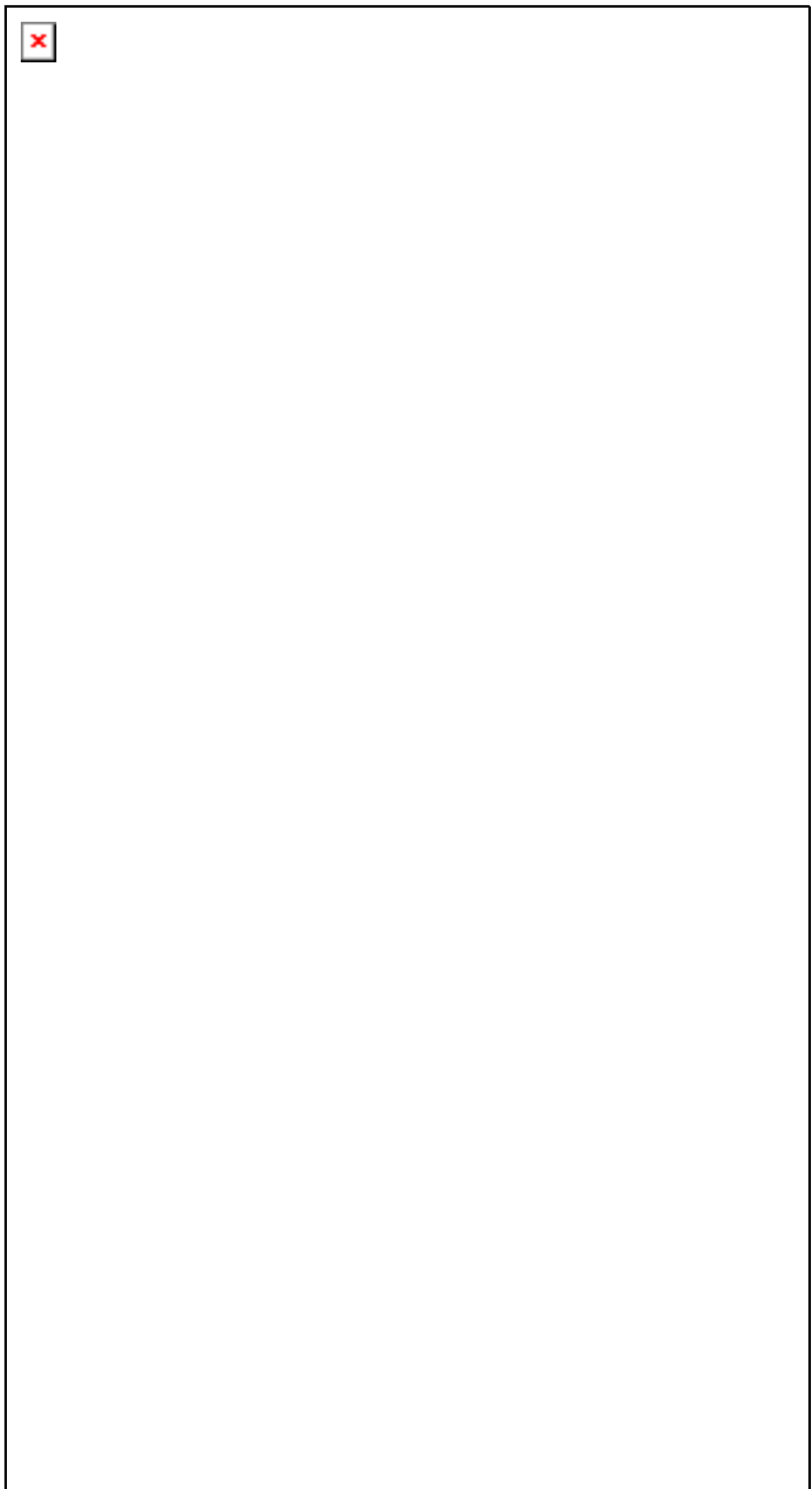

\section{RESULTS AND DISCUSSION}

Calculations for the Isolated Molecules. The ground-state molecular structures of the isolated molecules of the eight compounds depicted in the Introduction were obtained by fully optimized electronic structure calculations at the HF/6-31G*//HF/631G* level and also at the B3LYP/6-31G*//B3LYP/6-31G* level. The geometries obtained as these two levels were nearly identical; only those obtained at the latter level 
are reported here. In each case, normal mode analyses were carried out at the corresponding level to confirm that the calculated structure corresponded to a minimum energy conformation. As documented in the Supporting Information, the calculated CC bond distances and $\mathrm{CCC}$ bond angles in the ground states of the isolated molecules are in good agreement with the values that we or others have obtained from single-crystal X-ray diffraction or single-crystal neutron diffraction measurements of 9-MP, 1,9-DMP, 3,9DMP, 1,5-DMN , ${ }^{2}$ 2,6-DMN, 1,8-DMN $,{ }^{3} 9,10-\mathrm{DMP},{ }^{4}$ and 4,5-DMP. ${ }^{5}$

The internal rotation coordinate for the methyl groups is defined in this study as the dihedral angle $\beta$ between the following two bonds: whichever one of the two aromatic ring $\mathrm{CC}$ bonds flanking the position bearing the methyl group has the higher $\pi$ bond order, and whichever one of the three $\mathrm{CH}$ bonds in the methyl group makes the smallest dihedral angle $\beta$ with respect that ring CC bond. For each of the compounds in this study except 4,5-DMP the isolated molecules have calculated ground-state structures in which all the carbons are coplanar and each methyl group has a dihedral angle of $\beta=0^{\circ}$. As a consequence of the intramolecular crowding of the methyl groups in 4,5-DMP, the carbon skeleton of the phenanthrene ring system is twisted and the methyl groups in the isolated molecule were calculated to have dihedral angles of $\beta=42.9^{\circ}$ in the ground state.

To determine the rotation barriers for the ten types of methyl groups in the eight isolated molecules, fully optimized energy calculations of the classical potential energy surfaces for methyl rotations were carried out at the $\mathrm{HF} / 6-311+\mathrm{G}^{* *} / / \mathrm{HF} / 6-31 \mathrm{G}^{*}$ level and also at the B3LYP/6-311+G**//B3LYP/6-31G* level for a series of conformations with fixed values of $\beta$ ranging in $10^{\circ}$ steps from the ground-state energy minimum to the transition-state energy maximum. Only the results at the latter level are reported here. 
For all of the methyl groups except those in 4,5-DMP the calculated energy maximum has $\beta=60^{\circ}$; for $4,5-\mathrm{DMP}$ the calculated energy maximum has $\beta=102.1^{\circ}$. Five representative examples of the plots of the $\beta$-dependence of the potential energy are shown in Figure 1. The differences between the maximum and the minimum energies on the ten calculated potential energy surfaces were taken to be the energy barriers $\left(E_{\text {isol }}\right)$ for methyl rotation in the isolated molecules. The calculated values of $E_{i s o l}$ for the ten different methyl groups, ranging from $0.4 \mathrm{kcal} / \mathrm{mol}$ to $2.8 \mathrm{kcal} / \mathrm{mol}$, are given in Table 1 .

The rotational transition states were also independently obtained by locating the first-degree saddle points on the B3LYP/6-31G*//B3LYP/6-31G* potential energy surfaces using standard techniques. Normal mode analyses at the B3LYP/631G*//B3LYP/6-31G* level of the geometries obtained by this approach confirmed that they are indeed the transition states. There were negligible numerical differences between the transition-state energies obtained from this method and those obtained from the potential energy surface scans.

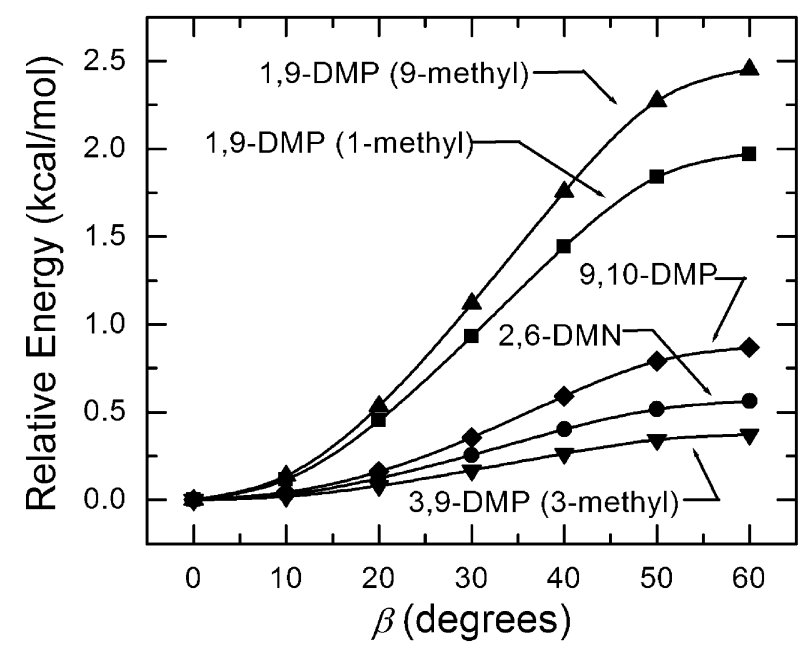

Figure 1. Calculated potential energies versus $\beta$ exemplified for five of the isolated molecules. 
Table 1. Calculated Potential Energy Barriers for Methyl Rotation in the Isolated Molecules and in the Central Molecules of the Clusters, and Experimental NMR Activation Energies ${ }^{a}$

\begin{tabular}{lcccccc}
\hline compd & $\mathrm{CH}_{3}$ & $E_{\text {isol }}$ & $E_{\text {clust }}$ & $E_{\text {inter }}{ }^{b}$ & $E_{\text {nmr }}$ & $E_{\text {clust }}$ \\
& grp & calc & calc & calc & $\operatorname{expt}^{c}$ & $-E_{n m r}$ \\
\hline 9-MP & $9 A^{d}$ & 2.5 & 3.2 & 0.7 & $2.5^{e}$ & +0.7 \\
9-MP & $9 B^{d}$ & 2.5 & 2.7 & 0.2 & $2.5^{e}$ & +0.2 \\
1,9-DMP & 9 & 2.5 & 3.2 & 0.7 & $2.9^{f}$ & +0.3 \\
3,9-DMP & 9 & 2.5 & 3.3 & 0.8 & $2.7^{e}$ & +0.6 \\
1,9-DMP & 1 & 2.0 & 2.4 & 0.4 & $2.2^{f}$ & +0.2 \\
1,5-DMN & $1^{g}$ & 2.0 & $3.0^{g}$ & 1.0 & $2.3^{h}$ & +0.7 \\
1,5-DMN & $5^{g}$ & 2.0 & $2.6^{g}$ & 0.6 & $2.3^{h}$ & +0.3 \\
3,9-DMP & 3 & 0.4 & 1.1 & 0.7 & $1.2^{e}$ & -0.1 \\
2,6-DMN & 2,6 & 0.6 & 0.6 & 0.0 & $0.4^{i}$ & +0.2 \\
1,8-DMN & $1^{g}$ & 2.8 & $3.4^{g}$ & 0.6 & $3.2^{h, j}$ & +0.2 \\
1,8-DMN & $8^{g}$ & 2.8 & $3.2^{g}$ & 0.4 & $3.2^{h, j}$ & 0.0 \\
9,10-DMP & $9^{g}$ & 0.9 & 1.1 & 0.2 & $1.2^{k}$ & -0.1 \\
9,10-DMP & $10^{g}$ & 0.9 & 1.1 & 0.2 & $1.2^{k}$ & -0.1 \\
4,5-DMP & $4^{g}$ & 1.8 & $2.6^{g}$ & 0.8 & $2.7^{l}$ & -0.1 \\
4,5-DMP & $5^{g}$ & 1.8 & $2.5^{g}$ & 0.7 & $2.7^{l}$ & -0.2
\end{tabular}


${ }^{a}$ All energies are in $\mathrm{kcal} / \mathrm{mol} .{ }^{b} E_{\text {inter }}=$ $E_{\text {clust }}-E_{\text {isol. }}{ }^{c}$ Typical uncertainties are $\leq 0.1$

$\mathrm{kcal} / \mathrm{mol} .{ }^{d}$ The unit cell in the crystal has two independent molecules, $A$ and $B .{ }^{e}$ Data taken from Reference 6 and re-analyzed. ${ }^{f}$ Data taken from Reference 7 and re-analyzed. ${ }^{g}$ The two methyl groups have different local environments in the cluster; the position numbers were assigned arbitrarily. ${ }^{h}$ Data taken from Reference 8. ${ }^{i}$ Data taken from Reference 8 and re-analyzed. ${ }^{j}$ A puzzling value of $7.8 \mathrm{kcal} / \mathrm{mol}$ was reported in Reference 10 on the basis of variabletemperature single-crystal neutron diffraction experiments. ${ }^{k}$ This work. ${ }^{l}$ Data taken from Reference 9.

The range of magnitudes of $E_{\text {isol }}$ in Table 1 can be discussed in terms of the longestablished ${ }^{11-13}$ electronic and steric effects that are illustrated in Figure 2 for the simple examples of 1-methylnaphthalene and 2-methylnaphthalene. The electronic effects in both of these molecules are attributed to orbital overlap interactions between the methyl groups and the aromatic rings. These interactions are most stabilizing for the methyl 
conformations in which one of the $\mathrm{CH}$ bonds is eclipsed with the flanking $\mathrm{CC}$ bond of the aromatic ring having the larger $\pi$-bond order, and they are least stabilizing for the methyl conformations in which one of the $\mathrm{CH}$ bonds is eclipsed with the flanking $\mathrm{CC}$ bond of the aromatic ring having the smaller $\pi$-bond order. ${ }^{11-13}$ The steric effect is illustrated in Figure 2 for the methyl rotation in 1-methylnaphthalene, in which the transition state is raised in energy by the steric crowding between the in-plane hydrogen of the peri-methyl group and the peri hydrogen on the other aromatic ring. No comparable steric crowding arises during the methyl rotation in 2-methylnaphthalene.

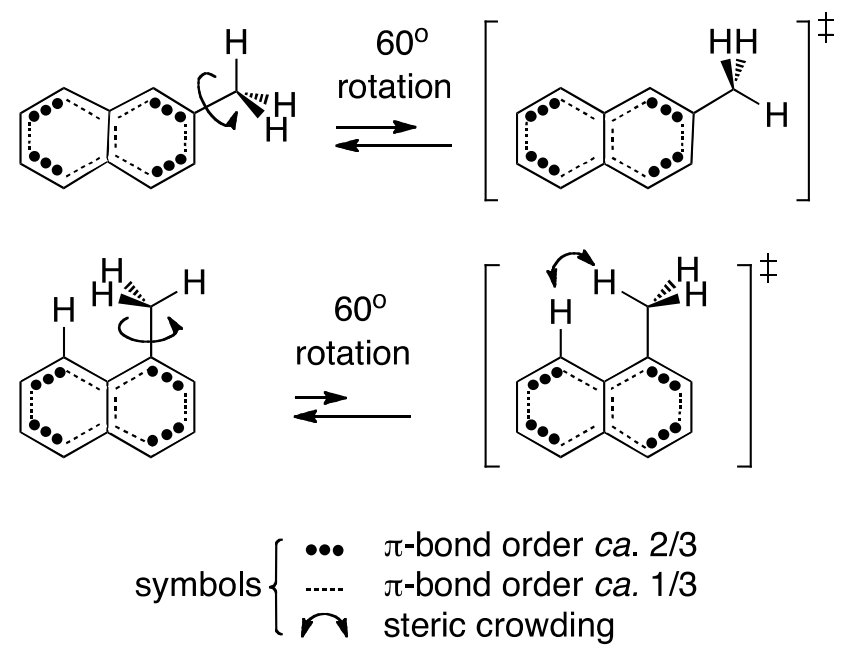

Figure 2. Diagrammatic representations of the types of electronic and steric effects thought to contribute to the methyl rotation barriers in two simple methyl-substituted aromatic molecules.

As indicated in Figure 3 and Table 1, an isolated molecule of 1,9-DMP has a larger calculated rotation barrier for the 9-methyl group $\left(E_{i s o l}=2.5 \mathrm{kcal} / \mathrm{mol}\right)$ than for the 
1-methyl group $\left(E_{\text {isol }}=2.0 \mathrm{kcal} / \mathrm{mol}\right)$. Since both methyl groups are peri, and therefore would be expected to experience similar steric effects, the difference between these two barriers can be attributed mainly to the electronic effect ${ }^{11-13}$ discussed above. Specifically, our X-ray diffraction analysis of 1,9-DMP showed that the bond distances for the C9-C10 bond (1.345 $)$ and the C9-C8a bond (1.444 $\AA$ ) differ by $0.099 \AA$, whereas the bond distances for the $\mathrm{C} 1-\mathrm{C} 2$ bond $(1.373 \AA$ ) and the $\mathrm{C} 1-\mathrm{C} 10 \mathrm{a}$ bond $(1.419$ $\AA$ ) differ by only $0.046 \AA$. Therefore the difference in $\pi$-bond orders of the two flanking ring bonds would be larger at the 9-position than at the 1-position, which accounts qualitatively for the 9-methyl group having the larger value of $E_{\text {isol }}$.

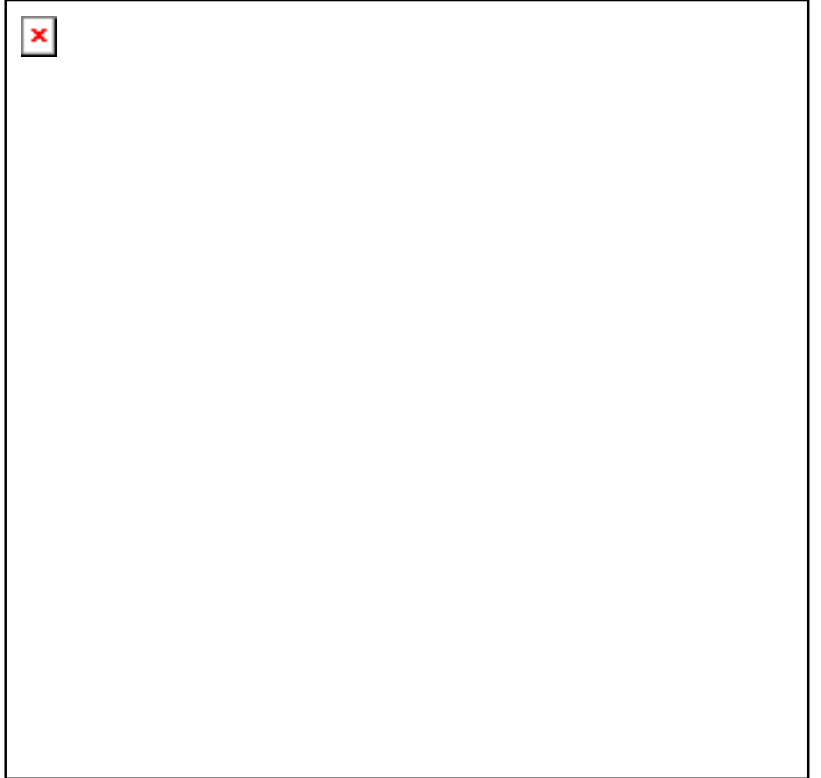

Figure 3. The electronic effect accounts for the calculated $0.5 \mathrm{kcal} / \mathrm{mol}$ potential energy difference between the two transition states. 
As indicated in Table 1, the rotation barrier of $0.9 \mathrm{kcal} / \mathrm{mol}$ for the 9-methyl group in 9,10-DMP is much lower than the rotation barriers of $2.5 \mathrm{kcal} / \mathrm{mol}$ for the 9-methyl groups in 9-MP, 1,9-DMP, and 3,9-DMP. Figure 4 illustrates how this can be explained qualitatively by noting that both the ground state and the transition state in 9,10-DMP experience comparable intramolecular steric crowding.

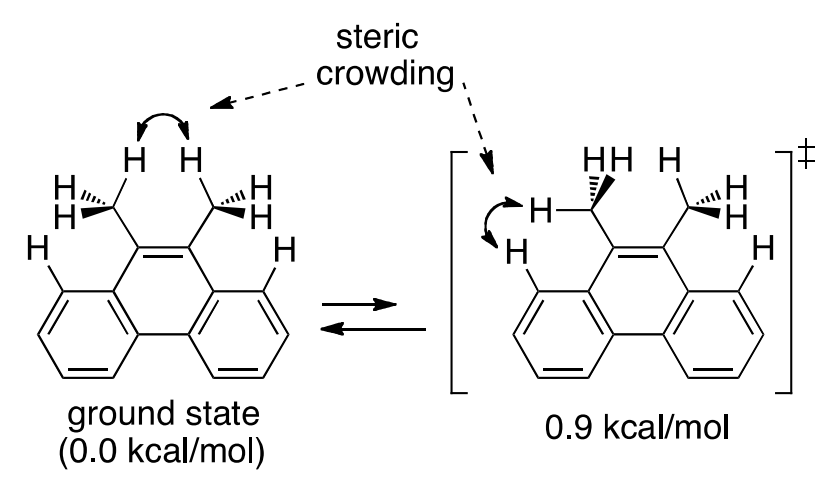

Figure 4. Off-setting steric destabilization explains why the rotation barrier is so small.

Intramolecular steric crowding between two methyl groups also is involved in the methyl rotation in 1,8-DMN. Our calculations of the two-dimensional potential energy surface of 1,8 -DMN as a function of the dihedral angles $\beta$ for the rotations of both methyl groups reveal the cooperative rotation process illustrated in Figure 5, in which one of the methyl groups can be seen to act as a kind of gatekeeper for the rotation of the other methyl group. In the first half of the rotation process both methyl groups rotate cooperatively, one by $30^{\circ}$ and the other by $11^{\circ}$, after which the former methyl group continues its rotation for another $30^{\circ}$ to reach the transition state with $\beta=60^{\circ}$ while the "gatekeeper" methyl group reverses its direction of rotation to go back to $\beta=0^{\circ}$. 


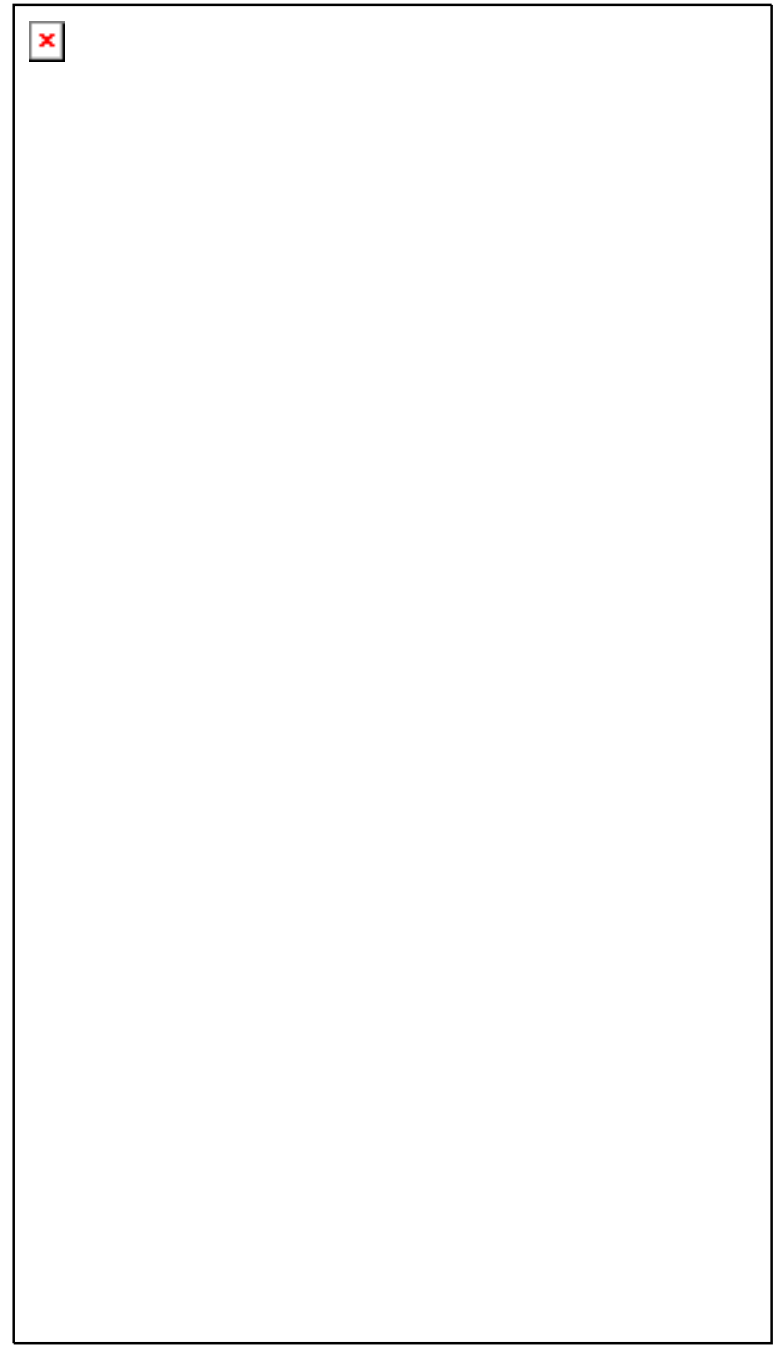

Figure 5. An edge-view diagram of an isolated molecule of $1,8-\mathrm{DMN}$ illustrating the $60^{\circ}$ rotation of the 1-methyl group, the two cooperative $11^{\circ}$ rotations of the 8-methyl group, and the calculated potential energies relative to the ground state along this rotation pathway. 
The sequence in which the compounds are listed in Table 1 is organized to show that the methyl groups in this study can be sorted into the following four categories on the basis of the magnitudes of the barriers and the types of ring carbons to which the rotating methyl groups are attached: (1) the highest barriers were found for the peri methyls at the 9-positions in 9-MP, 1,9-DMP, and 3,9-DMP (all $2.5 \mathrm{kcal} / \mathrm{mol}$ ) because both electronic and steric effects are contributing to raising the transition-state energies; (2) somewhat lower barriers were found for the peri methyls at the 1-positions in 1,9-DMP and 1,5DMN (all $2.0 \mathrm{kcal} / \mathrm{mol}$ ) because the differences in the $\pi$-bond orders of the two flanking ring bonds at the 1-positions are less than the corresponding differences at the 9-positions in phenanthrenes, thus resulting in a smaller electronic effect; (3) much lower barriers were found for the methyl groups in $2,6-\mathrm{DMN}(0.6 \mathrm{kcal} / \mathrm{mol})$ and the 3 -methyl group in 3,9-DMP $(0.4 \mathrm{kcal} / \mathrm{mol})$ because these are non-peri methyls that are flanked on both sides by ring carbons that each bear a hydrogen substituent, thus rendering steric effects essentially inoperative; and (4) molecules such as 1,8-DMN, 9,10-DMP, and 4,5-DMP are special cases because their methyl rotation barriers are influenced by the intramolecular steric crowding of the two methyl groups against one another in addition to the types of electronic and steric effects that are involved in the other three categories.

Calculations for the Molecules in the Clusters. To calculate the barriers for methyl rotation in the crystalline environment, the Mathematica code DiracCrystal ${ }^{14}$ was created to construct clusters of each type of molecule in which the coordinates of the carbon atoms were fixed at the positions determined experimentally for the crystals by either X-ray diffraction or neutron diffraction studies. The coordinates of the hydrogens in the clusters were then determined by electronic structure calculations at the HF/3- 
21G//HF/3-21G level. As documented in the Supporting Information, the reliability of these calculations is indicated by the fact that the $\mathrm{CH}$ bond lengths obtained from the calculations for each of the $\mathrm{CH}$ bonds in 1,5-DMN and 1,8-DMN and the corresponding $\mathrm{CH}$ bond lengths obtained by single-crystal neutron diffraction measurements ${ }^{2,3}$ differed from one another with a root mean square deviation of less than $0.02 \AA$.

Although there are only ten different types of methyl groups in the eight isolated molecules, it proved necessary to construct a total of fifteen different clusters. For example, the X-ray diffraction measurements for 9-MP show that the unit cell of the crystal contains two crystallographically independent molecules in which the methyl groups experience different local environments. In addition, the pairs of methyl groups that are equivalent by symmetry in each of the isolated molecules of 1,5-DMN, 1,8DMN, 9,10-DMP, and 4,5-DMP are not equivalent by symmetry in the crystals, and therefore two separate clusters needed to be constructed for each of these four molecules. Each of the fifteen clusters was built around a central molecule, and included all the surrounding molecules that had any carbon or hydrogen atom within a fixed distance (typically between $6 \AA$ and $7 \AA$ ) of the Cm carbon atom of the methyl group of interest on the central molecule. The resulting clusters (see the Supporting Information) contained 8-13 molecules.

For the central molecule in each cluster, the $\beta$-dependence of the energy was calculated in two stages. In the first stage, a potential energy plot was computed at the B3LYP/6-31G* level for $15^{\circ}$ increments of $\beta$ for the methyl group on the central molecule (with additional calculations near the ground-state and transition-state conformations). In these first-stage calculations the bond angles and bond distances 
within the rotating central methyl group were held fixed, as were the positions for all the other atoms in the cluster. In the second-stage calculations the ground-state and transition-state structures obtained from the first-stage calculations were subjected to further geometry-optimizing calculations at the HF/3-21G level. In these second-stage calculations the bond angles and bond distances within the rotating methyl group on the central molecule were allowed to relax, as were the structural parameters of all of the ring hydrogens on the central molecule. In addition, for all of the other molecules in the cluster the dihedral angles of their methyl groups were allowed to relax and also the locations of their ring hydrogens were allowed to relax by out-of-plane bending with respect to the plane of the aromatic ring to which they were bonded. Finally, the energies of these partially relaxed ground-state and transition-state structures for each cluster were obtained by single-point calculations at the B3LYP/6-31G* level. The resulting potential energy difference between these two structures was taken as the rotation barrier for the central molecule in the cluster, which is designated here as $E_{\text {clust. }}$ The values of $E_{\text {clust }}$ are given in Table $1 .{ }^{15}$ These final values of $E_{\text {clust }}$ were each lower in energy, by amounts ranging from $0.4 \mathrm{kcal} / \mathrm{mol}$ to $1.4 \mathrm{kcal} / \mathrm{mol}$, than the corresponding preliminary values of the barriers in the clusters that had been obtained after the first-stage calculations.

There are some small differences in the calculated molecular structures for the central molecules in the clusters as compared with the calculated molecular structures for the isolated molecules. For example, although the carbon skeletons (except for 4,5DMP) are coplanar in the isolated molecules, they are found by X-ray or neutron diffraction measurements to be slightly twisted in the crystals (and therefore also in the clusters). Also, as shown in Table 2, the calculated values of the dihedral angles of the 
central molecules in the clusters $\left(\beta_{\text {clust }}\right)$ are larger than those in the isolated molecules $\left(\beta_{\text {isol }}\right)$ by amounts up to $15^{\circ}$, as one would expect from intermolecular steric interactions.

Table 2. Calculated Dihedral Angles $\beta$ in the Isolated Molecules and the Central Molecules in the Clusters

\begin{tabular}{lcccc}
\hline compd & $\mathrm{CH}_{3}$ & dihedral & $\beta_{\text {isol }}{ }^{a}$ & $\beta_{\text {clust }}{ }^{a}$ \\
& pos. & angle & calc & calc \\
\hline 9-MP & $9 A^{b}$ & H-Cm-C9-C10 & 0.0 & 1.8 \\
9-MP & $9 B^{b}$ & H-Cm-C9-C10 & 0.0 & 1.2 \\
1,9-DMP & 9 & H-Cm-C9-C10 & 0.0 & 1.4 \\
3,9-DMP & 9 & H-Cm-C9-C10 & 0.0 & 2.6 \\
1,9-DMP & 1 & H-Cm-C1-C2 & 0.0 & 4.7 \\
1,5-DMN & $1^{c}$ & H-Cm-C1-C2 & 0.0 & $0.2^{c}$ \\
1,5-DMN & $5^{c}$ & H-Cm-C5-C6 & 0.0 & $0.7^{c}$ \\
3,9-DMP & 3 & H-Cm-C3-C4 & 0.0 & 7.2 \\
2,6-DMN & 2,6 & H-Cm-C2-C1 & 0.0 & 4.3 \\
1,8-DMN & $1^{c}$ & H-Cm-C1-C2 & 0.0 & $0.0^{c}$ \\
1,8-DMN & $8^{c}$ & H-Cm-C8-C7 & 0.0 & $3.8^{c}$ \\
9,10-DMP & $9^{c, d}$ & H-Cm-C9-C10 & 0.0 & $15.0^{c, d}$ \\
9,10-DMP & $10^{c, d}$ & H-Cm-C9-C10 & 0.0 & $15.0^{c, d}$ \\
4,5-DMP & $4^{c}$ & H-Cm-C4-C3 & 42.9 & $45.4^{c}$ \\
4,5-DMP & $5^{c}$ & H-Cm-C5-C6 & 42.9 & $49.1^{c}$
\end{tabular}


${ }^{a}$ In degrees. ${ }^{b}$ The crystal unit cell has

two inequivalent molecules, $A$ and $B .{ }^{c}$ The two

methyl groups are inequivalent in the cluster;

the two position numbers are assigned

arbitrarily. ${ }^{d}$ See Reference 15 .

In an attempt to evaluate the separate intramolecular and intermolecular contributions to the rotation barriers $E_{\text {clust }}$, we have assumed as a first approximation that the magnitude of the intramolecular component $E_{\text {intra }}$ is equal to $E_{\text {isol }}$ and the magnitude of the intermolecular component $E_{\text {inter }}$ is equal to $E_{\text {clust }}-E_{\text {isol. }}$. As shown in Table 1, the fifteen calculated values of $E_{\text {inter }}$ that were obtained using this approach range from 0.0 $\mathrm{kcal} / \mathrm{mol}$ to $1.0 \mathrm{kcal} / \mathrm{mol}$. In principle, an intermolecular steric interaction could either increase or decrease the barrier for the rotation of the $\mathrm{Cm}$ methyl group, depending on whether the destabilizing steric crowding of that methyl group against an adjacent molecule in the cluster is more severe in the transition state or more severe in the ground state for that rotation. ${ }^{16}$ In view of the conceptual approximations of our assumption that $E_{\text {inter }}=E_{\text {clust }}-E_{\text {isol }}$, as well as the numerical uncertainties that are inherent for the values of $E_{\text {inter }}$ because they are obtained as the differences between the computed values of $E_{\text {clust }}$ and $E_{\text {isol }}$, the only conclusion we wish to draw with regard to intermolecular steric effects is that they seem to have a relatively small influence on the magnitudes of the methyl rotation barriers in the clusters of our eight compounds. 


\section{Solid State NMR Relaxation Measurements of the Activation Energies $\boldsymbol{E}_{n m r}$}

for Methyl Rotation in the Crystals. In our solid-state NMR nuclear-spin-relaxation experiments we measure the ${ }^{1} \mathrm{H}$ spin-lattice relaxation rates $1 / T_{1}$ as a function of the NMR frequency $\omega / 2 \pi$ and the absolute temperature $T{ }^{6,7}$ The observed relaxation rates are interpreted in terms of Bloch-Wangsness-Redfield theory. ${ }^{17-20}$ In the hightemperature short-correlation-time limit the relaxation rate can be expressed as $1 / T_{1}=C \tau$, where $C$ is a constant whose numerical value depends on other known constants and geometric parameters,,${ }^{6,7}$ and where $\tau$ is the mean time between $2 \pi / 3$ rotational hops of the methyl groups in a random (Poisson) process. As a consequence of this rotation, the three proton nuclei in the methyl group create a local time-dependent magnetic field. The ${ }^{1} \mathrm{H}$ spin-lattice relaxation is induced by the Fourier component of this local timedependent magnetic field that matches the NMR frequency. The mean time between rotational hops $\tau$ is modeled by the Arrhenius relationship $\tau=\tau_{\infty} \exp \left(E_{n m r} / R T\right)$, where $E_{n m r}$ is the activation energy for methyl rotation, $\tau_{\infty}$ is a pre-exponential factor, and $R$ is the gas constant. It follows that $1 / T_{1}=C \tau_{\infty} \exp \left(E_{n m r} / R T\right)$, which allows the extraction of the value of $E_{n m r}$ from the slope of the high-temperature region of a plot of $\ln \left(1 / T_{1}\right)$ vs. $T^{-1}$.

The ten experimental values of $E_{n m r}$ in Table 1 include one value reported here (9,10-DMP), five values obtained by re-analysis ${ }^{21}$ of data from earlier publications of ours (9-MP, ${ }^{6} 1,9-\mathrm{DMP},{ }^{7}$ and 3,9-DMP $\left.{ }^{6}\right)$, and four values taken from earlier publications of others $\left(1,5-\mathrm{DMN},{ }^{8} 1,8-\mathrm{DMN},{ }^{8} 2,6-\mathrm{DMN},{ }^{8}\right.$ and $\left.4,5-\mathrm{DMP}^{9}\right)$.

The differences between the fifteen calculated values of $E_{\text {clust }}$ and the corresponding experimental values of $E_{n m r}$ are given in Table 1. These $E_{c l u s t}-E_{n m r}$ differences range from $-0.2 \mathrm{kcal} / \mathrm{mol}$ to $+0.7 \mathrm{kcal} / \mathrm{mol}$ with a mean value of +0.2 
$\mathrm{kcal} / \mathrm{mol}$ and a standard deviation of $0.3 \mathrm{kcal} / \mathrm{mol}$. As described in the following section, there are theoretical reasons ${ }^{22,23}$ to expect a small bias toward $E_{\text {clust }}$ being slightly larger than $E_{n m r}$ for the rotation of methyl groups.

The Relationship between the Calculated Potential Energy Barriers ( $\boldsymbol{E}_{\text {isol }}$ and $\left.\boldsymbol{E}_{\text {clust }}\right)$ and the Experimental NMR Activation Energies $\left(\boldsymbol{E}_{n m r}\right)$. An ab initio electronic structure calculation for methyl rotation provides a potential energy surface from which a barrier $\left(E_{\text {isol }}\right.$ or $\left.E_{\text {clust }}\right)$ is obtained as the difference in potential energy between the highest and lowest points on the calculated surface. In contrast, an NMR spin-lattice relaxation rate experiment determines an Arrhenius activation energy $\left(E_{n m r}\right)$. The quantitative relationship between calculated potential energy barriers and experimentally measured Arrhenius activation energies for methyl rotation has been considered in earlier theoretical studies. For example, Kowalewski and Liljefors ${ }^{22}$ used absolute rate theory to calculate the activation energies for the internal rotation of a methyl group (attached to a hypothetical rigid molecule) for two representative values of the three-fold potential energy barrier $V_{3}(2.04 \mathrm{kcal} / \mathrm{mol}$ and $3.40 \mathrm{kcal} / \mathrm{mol})$ at three temperatures $(200 \mathrm{~K}, 250 \mathrm{~K}$, and $333 \mathrm{~K}$ ). Their calculations showed that the potential energy barriers $V_{3}$ (corresponding to our $E_{\text {isol }}$ and $E_{\text {clust }}$ values) were larger than the activation energies (corresponding to our $E_{n m r}$ values) by about $0.1 \mathrm{kcal} / \mathrm{mol}$. Using a different theoretical approach, Edholm and Blomberg ${ }^{23}$ reached a similar conclusion about calculated $V_{3}$ barriers being larger than experimental activation energies for methyl rotations. 


\section{CONCLUSIONS}

The close correspondence between the calculated values of $E_{\text {clust }}$ and the experimental values of $E_{n m r}$ in Table 1 suggests that the cluster method we have developed for calculating the energy barriers for methyl rotation in crystals appears to have useful predictive value for the experimental activation energies determined by NMR spin-lattice relaxation rate measurements. Not only can computations of this type lend confidence to the reliability of the NMR experiments, but also the experimentally observed NMR activation energies can lend confidence to the reliability of the computational methods. In addition, any surprising disparities that might be found in the future between values of $E_{c l u s t}$ and $E_{n m r}$ in other systems could prompt further investigations to find the source of the discrepancy. Our computational approach also seems to be reasonably successful at giving calculated values of $E_{\text {clust }}$ in rather close agreement with experimental values of $E_{n m r}$ for such disparate compounds as $1,5-\mathrm{DMN}$ (which experiences a combination of an electronic effect and a peri steric effect) and 2,6DMN (which experiences only an electronic effect). Finally, our results provide additional support for the usefulness of the traditionally invoked contributions of steric and electronic factors to the rotation barriers for methyl substituents on aromatic rings.

\section{EXPERIMENTAL SECTION}

Characterizations of Compounds. Characterization data are given below for the five compounds we used in our X-ray crystallographic determinations of the molecular and crystal structures for 9-MP, 1,9-DMP, 3,9-DMP and 2,6-DMP, and also in our solidstate NMR measurements of the spin-lattice relaxation rates for 9-MP, 1,9-DMP, 3,9- 
DMP and 9,10-DMP. The ${ }^{1} \mathrm{H}$ NMR spectra and the complete GC-MS results (chromatograms and mass spectra) for these five compounds are included in the Supporting Information.

9-Methylphenanthrene (9-MP). Synthesized by photocyclization and recrystallized from methanol: ${ }^{6} \mathrm{mp} 90.0-92.0{ }^{\circ} \mathrm{C}$ (lit. $\left.{ }^{24} \mathrm{mp} 91.5-92.5^{\circ} \mathrm{C}\right) ;{ }^{1} \mathrm{H}$ NMR $(400$ $\mathrm{MHz}, \mathrm{CDCl}_{3}, \delta$ ): $8.71(\mathrm{~m}, 1 \mathrm{H}), 8.63$ (br d, $J=8.2 \mathrm{~Hz}, 1 \mathrm{H}$ ), 8.04 (br dd, $J=7.0 \mathrm{H}, 2.5$ $\mathrm{Hz}, 1 \mathrm{H}), 7.79$ (br dd, $J=8.2 \mathrm{~Hz}, 2.0 \mathrm{~Hz}, 1 \mathrm{H}), 7.67-7.60$ (m, $2 \mathrm{H}), 7.59-7.22(\mathrm{~m}, 3 \mathrm{H})$, 2.72 (br s, 3 H); GC-MS m/z (\% rel. intensity, ion): $192\left(100, \mathrm{M}^{+}\right), 191\left(52, \mathrm{M}^{+}-\mathrm{H}\right)$. 1,9-Dimethylphenanthrene (1,9-DMP). Synthesized by photocyclization and recrystallized from methanol: ${ }^{7} \mathrm{mp} 86.8-87.6$ (lit. $\left.{ }^{25} \mathrm{mp} 87-88^{\circ} \mathrm{C}\right) ;{ }^{1} \mathrm{H}$ NMR $(400 \mathrm{MHz}$, $\left.\mathrm{CDCl}_{3}, \delta\right): 8.72(\mathrm{~m}, 1 \mathrm{H}), 8.53(\mathrm{br} \mathrm{d}, J=8.3 \mathrm{~Hz}, 1 \mathrm{H}), 8.05(\mathrm{~m}, 1 \mathrm{H}), 7.77(\mathrm{br} \mathrm{s}, 1 \mathrm{H})$, 7.66-7.59 (m, $2 \mathrm{H}), 7.47$ (dd, $J=8.1 \mathrm{~Hz}, 7.3 \mathrm{~Hz}, 1 \mathrm{H}) 7.40(\mathrm{~d}, J=7.0 \mathrm{~Hz}, 1 \mathrm{H}), 2.76(\mathrm{~s}, 3$ H), 2.72 (s, $3 \mathrm{H})$; GC-MS m/z (\% rel. intensity, ion): $206\left(100, \mathrm{M}^{+}\right), 191\left(51, \mathrm{M}^{+}-\mathrm{CH}_{3}\right)$. 3,9-Dimethylphenanthrene (3,9-DMP). Synthesized by photocyclization and recrystallized from methanol: ${ }^{6} \mathrm{mp} 58.0-59.6{ }^{\circ} \mathrm{C}\left(\mathrm{lit} .{ }^{26} \mathrm{mp} 62{ }^{\circ} \mathrm{C}\right) ;{ }^{1} \mathrm{H}$ NMR $(400 \mathrm{MHz}$, $\left.\mathrm{CDCl}_{3}, \delta\right): 8.69(\mathrm{~m}, 1 \mathrm{H}), 8.42(\mathrm{br} \mathrm{s}, 1 \mathrm{H}), 8.02(\mathrm{~m}, 1 \mathrm{H}), 7.69(\mathrm{~d}, J=8.0 \mathrm{~Hz}, 1 \mathrm{H}), 7.62$ (m, 2 H), 7.53 (br s, $1 \mathrm{H}), 7.38$ (dd, $J=8.0 \mathrm{~Hz}, 1.3 \mathrm{~Hz}, 1 \mathrm{H}), 2.70$ (br s, $3 \mathrm{H}), 2.59$ (s, 3 H); GC-MS m/z (\% rel. intensity, ion): $206\left(100, \mathrm{M}^{+}\right), 191\left(45, \mathrm{M}^{+}-\mathrm{CH}_{3}\right)$.

2,6-Dimethylnaphthalene (2,6-DMN). A commercial sample (Rütgerswerke) was recrystallized from ethanol-benzene: $\mathrm{mp} 109.5-110{ }^{\circ} \mathrm{C}\left(\right.$ lit. $\left.{ }^{27} \mathrm{mp} 110.3-111.0{ }^{\circ} \mathrm{C}\right) ;{ }^{1} \mathrm{H}$ NMR (400 MHz, $\left.\mathrm{CDCl}_{3}, \delta\right): 7.64$ (d, $\left.J=7.3 \mathrm{~Hz}, 2 \mathrm{H}\right), 7.55$ (br s, 2H), 7.27 (br d, $J=8.2$ Hz, 2 H), 2.48 (s, 6 H); GC-MS m/z (\% rel. intensity, ion): $156\left(100, \mathrm{M}^{+}\right), 141\left(71, \mathrm{M}^{+}-\right.$ $\left.\mathrm{CH}_{3}\right)$. 
9,10-Dimethylphenanthrene (9,10-DMP). Recrystallized from methanol: mp 143$143.5^{\circ} \mathrm{C}\left(\right.$ lit. $\left.^{28} \mathrm{mp} 142.5-143{ }^{\circ} \mathrm{C}\right) ;{ }^{1} \mathrm{H}$ NMR (400 MHz, $\left.\mathrm{CDCl}_{3}, \delta\right): 8.70$ (m, $\left.2 \mathrm{H}\right), 8.11$ (m, 2 H), 7.60 (m, 4 H), 2.73 (s, $6 \mathrm{H})$; GC-MS m/z (\% rel. intensity, ion): $206\left(100, \mathrm{M}^{+}\right)$, $191\left(100, \mathrm{M}^{+}-\mathrm{CH}_{3}\right)$.

X-ray Crystallographic Measurements. The molecular and crystal structures for 9-MP, 1,9-DMP, 3,9-DMP, and 2,6-DMN were obtained by single-crystal X-ray diffraction analyses using standard methods at low temperatures. ${ }^{29}$ The space groups for 9-MP and 3,9-DMP were uniquely assigned from systematic absences. The asymmetric unit for 9-MP contains two crystallographically independent molecules. The asymmetric unit for 1,9-DMP contains a half molecule on an inversion center. The space group for 1,9-DMP was found to be the non-centrosymmetric alternative due to the absence of an appropriately aligned mirror plane. All non-hydrogen atoms were anisotropically refined. The experimental results for these four compounds are given in the Supporting Information in Table S10 and in the CIF files.

Solid-State NMR Relaxation Measurements. The spin-lattice relaxation rate for 9,10-DMP was measured in the present work using standard techniques ${ }^{6,730}$ at temperatures $T$ ranging between $90 \mathrm{~K}$ and $295 \mathrm{~K}$ and at NMR frequencies of $22.5 \mathrm{MHz}$ and 53.0 MHz. Because the activation energy for methyl rotation in 9,10-DMP is so small (1.2 kcal/mol), only the high-temperature, frequency-independent, and linear behavior of $\ln \left(1 / T_{1}\right)$ versus $T^{-1}$ was observed throughout this temperature range. The activation energy was extracted from the slope of a plot of $\ln \left(1 / T_{1}\right)$ versus $T^{-1}$.

Electronic Structure Calculations. All the ab initio electronic structure calculations reported here were carried out using the Gaussian 03 program suite. ${ }^{31}$ 
Further details have been reported elsewhere for analogous calculations involving the rotations of methyl, isopropyl, and trifluoromethyl substituents on aromatic rings. ${ }^{32,33}$

Supporting Information. Calculated total energies in Hartrees and calculated structural coordinates for all the atoms in the eight molecules of interest in their ground states and also in their transition states for methyl rotation, both for the isolated single molecules and for the clusters; comparisons of the calculated ground-state structures of these molecules with those determined by X-ray or neutron diffraction studies; CIF files for the four X-ray structures reported here; proton NMR spectra and GC/MS data for 9MP, 1,9-DMP, 3,9-DMP, 2,6-DMN, and 9,10-DMP. This material is available free of charge via the Internet at http://pubs.acs.org.

\section{AUTHOR INFORMATION}

\section{Corresponding Author}

*E-mail: fmallory@brynmawr.edu

\section{Present Address}

${ }^{\Delta}$ Department of Chemistry, University of California, Berkeley, Berkeley, California 94720-1460, United States.

\section{ACKNOWLEDGMENT}

The cluster approach developed for the computations of the energy barriers for the rotations of methyl, tert-butyl, and trifluoromethyl substituents on crystalline aromatic 
compounds is described in the Ph.D. dissertation of Xianlong Wang, Bryn Mawr College, 2006. This work was presented in part by Xianlong Wang at three meetings: (a) the 228th ACS National Meeting, Philadelphia, PA, Aug. 22-26, 2004, COMP-037; (b) the 229th ACS National Meeting, San Diego, CA, March 13-17, 2005, COMP-287; and (c) the 230th ACS National Meeting, Washington, DC, Aug. 28-Sept. 1, 2005, COMP-023.

\section{REFERENCES}

(1) Methyl carbons are designated as $\mathrm{Cm}$ in this work.

(2) Wilson, C. C. Chem. Commun. 1997, 1281-1282.

(3) Wilson, C. C.; Nowell, H. New J. Chem. 2000, 24, 1063-1066.

(4) Johnson, O.; Jones, D. W. Z. Kristallogr. 1989, 189, 109-116.

(5) Imashiro, F.; Saika, A.; Taira, Z. J. Org. Chem. 1987, 52, 5727-5729.

(6) Conn, K. G.; Beckmann, P. A.; Mallory, C. W.; Mallory, F. B. J. Chem. Phys. 1987, $87,20-27$.

(7) Mallory, F. B.; Mallory, C. W.; Conn, K. G.; Beckmann, P. A. J. Phys. Chem. Solids 1990, 51, 129-134.

(8) von Schütz, J. U.; Wolf, H. C. Z. Naturforsch. A 1972, 27, 42-50.

(9) Takegoshi, K.; Imashiro, F.; Terao, T.; Saika, A. J. Chem. Phys. 1984, 80, 1089-1094.

(10) Wilson, C. C. Chem. Phys. Lett. 2002, 362, 249-254.

(11) Lu, K.-T.; Weinhold, F.; Weisshaar, J. C. J. Chem. Phys. 1995, 102, 67876805. 
(12) George, P.; Bock, C. W.; Stezowski, J. J.; Hildenbrand, T.; Glusker, J. P. J. Phys. Chem. 1988, 92, 5656-5666.

(13) Liljefors, T.; Allinger, N. L. J. Comput. Chem. 1985, 6, 478-480.

(14) The Mathematica code DiracCrystal is available on request from one of the authors (X. W.), and is free of charge for academic users.

(15) For the special case of 9,10-DMP the calculated values of $E_{\text {clust }}$ and $\beta_{\text {clust }}$ for the two slightly inequivalent methyl groups in the cluster turned out to be numerically indistinguishable using the number of significant figures we consider appropriate.

(16) Baudry, J. J. Am. Chem. Soc. 2006, 128, 11088-11093.

(17) Abragam, A. The Principles of Nuclear Magnetism; Oxford University Press: Oxford UK, 1961.

(18) Slichter, C. P. Principles of Magnetic Resonance, 3rd ed; Springer-Verlag: Berlin, 1990.

(19) Ernst, R. R.; Bodenhausen, G.; Wokaun, A. Principles of Nuclear Magnetic Resonance in One and Two Dimensions; Oxford University Press: Oxford UK, 1987.

(20) Kimmich, R. NMR Tomography, Diffusometry, Relaxometry; SpringerVerlag: Berlin, 1997.

(21) Our previously reported five values ${ }^{6,7}$ of $E_{n m r}$ were obtained using the Davidson-Cole method to fit simultaneously both the high-temperature and lowtemperature $\ln \left(1 / T_{1}\right)$ vs. $T^{-1}$ data. We now consider it more appropriate to use only the high-temperature data to evaluate $E_{n m r}$. The re-analyzed values of $E_{n m r}$ listed in Table 1 differ from the values reported earlier ${ }^{6,7}$ with a root mean square deviation of 0.1 $\mathrm{kcal} / \mathrm{mol}$. 
(22) Kowalewski, J.; Liljefors, T. Chem. Phys. Lett. 1979, 64, 170-174.

(23) Edholm, O.; Blomberg, C. Chem. Phys. 1981, 56, 9-14.

(24) Bradsher, C. K.; Tess, R. W. H. J. Am. Chem. Soc. 1939, 61, 2184-2185.

(25) Haworth, R. D.; Mavin, C. R. J. Chem. Soc, 1932, 2720-2723.

(26) Cologne, J.; Arsac, A. Bull. Soc. Chim. France 1954, 445-448.

(27) Berliner, E.; Falcione, D. M.; Riemenschneider, J. L. J. Org. Chem. 1965, 30, $1812-1815$.

(28) Bradsher, C. K.; Amore, S. T. J. Am. Chem. Soc. 1944, 66, 2180.

(29) Crystallographic data are available as CIF files deposited with the Cambridge Crystallographic Data Centre for 1,9-DMP (CCDC 298133), 9-MP CCDC (298134), and 3,9-DMP (CCDC 298135).

(30) Beckmann, P. A.; Buser, C. A.; Gullifer, K.; Mallory, F. B.; Mallory, C. W.; Rossi, G. M.; Rheingold, A. L. J. Chem. Phys. 2003, 118, 11129-11138.

(31) Gaussian 03, Revision B.05: Frisch, M. J.; Trucks, G. W.; Schlegel, H. B.; Scuseria, G. E.; Robb, M. A.; Cheeseman, J. R.; Montgomery, Jr., J. A.; Vreven, T.;

Kudin, K. N.; Burant, J. C.; Millam, J. M.; Iyengar, S. S.; Tomasi, J.; Barone, V.; Mennucci, B.; Cossi, M.; Scalmani, G.; Rega, N.; Petersson, G.A.; Nakatsuji, H.; Hada, M.; Ehara, M.; Toyota, K.; Fukuda, R.; Hasegawa, J.; Ishida, M.; Nakajima, T.; Honda, Y.; Kitao, O.; Nakai, H.; Klene, M.; Li, X.; Knox, J. E.; Hratchian, H. P.; Cross, J. B.; Bakken, V.; Adamo, C.; Jaramillo, J.; Gomperts, R.; Stratmann, R. E.; Yazyev, O.; Austin, A. J.; Cammi, R.; Pomelli, C.; Ochterski, J. W.; Ayala, P. Y.; Morokuma, K.; Voth, G. A.; Salvador, P.; Dannenberg, J. J.; Zakrzewski, V. G.; Dapprich, S.; Daniels, A. D.; Strain, M. C.; Farkas, O.; Malick, D. K.; Rabuck, A. D.; Raghavachari, K.; 
Foresman, J. B.; Ortiz, J. V.; Cui, Q.; Baboul, A. G.; Clifford, S.; Cioslowski, J.;

Stefanov, B. B.; Liu, G.; Liashenko, A.; Piskorz, P.; Komaromi, I.; Martin, R. L.; Fox, D. J.; Keith, T.; Al-Laham, M. A.; Peng, C. Y.; Nanayakkara, A.; Challacombe, M.; Gill, P. M. W.; Johnson, B.; Chen, W.; Wong, M. W.; Gonzalez, C.; and Pople, J. A.; Gaussian 03, Revision B.05, Gaussian, Inc., Wallingford CT, 2004.

(32) Wang, X.; Mallory, F. B.; Mallory, C. W.; Beckmann, P. A.; Rheingold, A. L.; Francl, M. M. J. Phys. Chem. A 2006, 110, 3954-3960.

(33) Wang, X.; Rheingold, A. L.; DiPasquale, A. G.; Mallory, F. B.; Mallory, C. W.; Beckmann, P. A. J. Chem. Phys. 2008, 128, 124502/1-124502/3. 